\title{
The Role of Integrated Healthcare Center (Posyandu) Cadres in Increasing Maternal and Child Health during COVID-19 Pandemic
}

\author{
Daevi Khairunisa ${ }^{1}$, Nurhasanah ${ }^{2}$, Tria Susanti ${ }^{3}$, Fitra Januardi ${ }^{4}$ \\ ${ }^{1,2,3}$ Department of Midwifery, Polytechnic of Aisyiyah Pontianak, Pontianak, Indonesia \\ ${ }^{4}$ Department of Information Technology, Polytechnic of Aisyiyah Pontianak, Pontianak, Indonesia \\ Corresponding Author: Daevi Khairunisa
}

DOI: https://doi.org/10.52403/ijrr.20220214

\begin{abstract}
Maternal and child health is health that covers all aspects to maintain optimal health status comprehensively in every life cycle. The COVID-19 pandemic has had a significant impact on maternal and child health services. Rapid environmental changes related to the Covid-19 pandemic outbreak that occurred indirectly caused Integrated Healthcare Center activities to weaken. The role of Integrated Healthcare Center cadres is highly expected in efforts to improve maternal and child health. The purpose of this study was to explore the role of Integrated Healthcare Center Cadres in improving maternal and child health during the Covid-19 pandemic.

The research design used descriptive qualitative. The main informants were Integrated Healthcare Center cadres in the working area of UPTD Community Health Center of Pontianak City. Supporting informants were coordinating midwives, nutrition officers, mothers of toddlers and pregnant women. The sampling technique used was accidental sampling. Data were collected through in-depth interviews and documentation studies.

The results of the study explained the role of cadres in improving maternal and child health including the implementation of Integrated Healthcare Center with the pick-up method and application of health protocols, monitoring of maternal and child health and reporting of Integrated Healthcare Center results through the Integrated Healthcare Center information system.
\end{abstract}

The conclusion of the study is that the active role of Integrated Healthcare Center cadres in carrying out Integrated Healthcare Center activities during the Covid-19 pandemic by obeying health protocols is expected to be one of the successes in services in the field of maternal and child health.

Keywords: The Role of Cadres, Integrated Healthcare Center, Maternal and Child Health, Covid-19 Pandemic

\section{INTRODUCTION}

To produce healthy, intelligent, and good-quality next generation, it is necessary to prepare and protect them from birth. Various efforts have been made by the government to provide health services and increase community participation in health development efforts. Maternal and child health is health that includes all aspects to maintain optimal health degrees throughout all life cycles, from pre-conception, conception, pregnancy, postpartum, newborn, infant, preschool, school, adolescent, adult to menopause ${ }^{1}$.

Coronavirus Disease 2019 (COVID19) is a respiratory disease caused by a new type of coronavirus that has never been previously identified in humans. One of the reasons underlying the global magnitude of the novel coronavirus disease (COVID-19) is its transmission by asymptomatic or presymptomatic people ${ }^{2}$. The government has declared Covid-19 as a non-natural disaster 
in the form of an outbreak/pandemic. This determination is followed by efforts to prevent the spread of the corona virus through social restrictions including crowd restrictions, travel restrictions, enforcement of isolation, postponement and cancellation of events, as well as closure of facilities and public service arrangements ${ }^{3}$.

In Indonesia, the Covid-19 pandemic has a significant impact on maternal and child health services ${ }^{4}$. A decrease in the number of visits to nutrition and maternal and child health services can lead to new nutrition and health problems. Data from the Ministry of Health of the Republic of Indonesia (Kemenkes RI) shows a decrease in the number of visits for antenatal care, as well as health services for infants, toddlers, and children since the pandemic was announced. A quick survey from the Ministry of Health of the Republic of Indonesia and UNICEF noted that more than half of health care facilities in Indonesia do not carry out immunization services properly. It was also recorded that only $19.2 \%$ of services such as Integrated Healthcare Center remained open during the pandemic. This has an effect on the nonoptimal monitoring of maternal and child health ${ }^{5}$.

The Ministry of Health of the Republic of Indonesia has a solution in order that the Integrated Healthcare Center will continue to be implemented during the COVID-19 pandemic $^{8}$. One of solutions to this problem is the Integrated Healthcare Center Technical Instructions recommended by the Ministry of the Republic of Indonesia issued with the hope that the Integrated Healthcare Center can continue to run by complying with the protocol ${ }^{3}$.

Based on data from the Nutrition officer of the Community Health Center of Pontianak in 2020 in January - March (before the Covid-19 pandemic), it is stated that there were $75.3 \%$ of the number of visits by toddlers/children; meanwhile, in April-December (during the Covid-19 pandemic) 19), there were $27 \%$ of the number of visits infants. This means that there is a $48.3 \%$ decrease in the number of visits by toddlers/children at the Integrated Healthcare Center in the working area of the UPTD Community Health Center of Pontianak during the Covid-19 pandemic. In addition, 11 toddlers/children with nutritional status Below the Red Line (BGM) were also found.

The lack of community participation and knowledge regarding the Integrated Healthcare Center work program during the Covid-19 pandemic in the working area of Pontianak Community Health Center indicates that the role of cadres has not functioned optimally. In addition, the presence of children who have the opportunity to experience malnutrition indicates that the mother's lack of knowledge in providing nutrition is also evidence of the lack of success of Integrated Healthcare Center activities. The importance of the role of cadres in fostering a positive perception of the community to understand, understand the function of the Integrated Healthcare Center so that hopes to improve public health, especially mothers and children, can be achieved. It is with this background that encourages researchers to conduct research with the title The Role of Integrated Healthcare Center Cadres in Improving Maternal and Child Health at the Community Health Center of Pontianak (Kampung Bali) in West Kalimantan.

\section{LITERATURE REVIEW}

Integrated Health-Service Center (Integrated Healthcare Center) is a form of community-based health effort (UKBM) which aims to provide health service facilities for mothers, infants and toddlers. All these activities are carried out from and by the community ${ }^{6}$. Integrated Healthcare Center is one of the health efforts that has community resources from, for, and with the community in obtaining basic health services to reduce the Maternal Mortality Rate (MMR) and Infant Mortality Rate $(\mathrm{IMR})^{7}$.

In the implementation of Integrated Healthcare Center program activities, it 
cannot be separated from the role of Integrated Healthcare Center cadres who come from women in the community. Integrated Healthcare Center cadres who come from the surrounding community are willing and able to volunteer to carry out their duties at the Integrated Healthcare Center and have received training on "health services for the community ${ }^{7}$. The role of cadres is to take responsibility, develop capabilities, become actors, and pioneers as well as leaders who move the community based on the principles of independence and togetherness. When the Integrated Healthcare Center services provided get the sympathy of the community, the presence and role of cadres becomes important and strategic, which in turn will have a positive impact on public awareness and participation ${ }^{9}$.

\section{MATERIALS \& METHODS}

This research uses descriptive qualitative research and the sampling technique is accidental sampling. The main informants in the study were 8 people, namely the Integrated Healthcare Center Cadre in the Community Health Center of Pontianak (Kampung Bali), while the supporting informants or triangulation from this study were 4 people, namely the Coordinating Midwife at the Community Health Center, nutrition officers, and mothers of infants/toddlers/children and pregnant women participating in Integrated Healthcare Center.

The present research was conducted from January to February 2021. The validity test used was a construct test using expert judgment. There were three experts in accordance with the scope of the research. The role of cadres in improving maternal and child health during the Covid-19 pandemic was measured by in-depth interviews and documentation studies. The instrument used in this research was a semistructured interview guide with open-ended questions.

\section{Statistical Analysis}

The data analysis used in this study adopted the model of Miles \& Hubberman which consisted of 3 activities, namely data reduction, data presentation, conclusion drawing and verification.

\section{RESULT}

The main informants consisting of 8 people were aged between 45 and 59 years. The education level of the informants was seven people with high school education and one person with junior high school education level. All key informants were Housewives. There were four Supporting Informants, one is a Coordinating Midwife with the age of 51 years and one person is a nutrition officer with the age of 32 years, while the two supporting informants were mothers of toddlers, members of the Integrated Healthcare Center with the last education level of high school and household work, and a pregnant woman with the last education is junior high school with a job as a housewife. All informants during the interview were quite cooperative, so that the researcher was able to complete the interview process perfectly.

\section{a. Cadre Knowledge about Maternal and Child Health}

According to informants, maternal and child health is carried out by monitoring from pregnant women to childbirth, providing counseling on Early Initiation of Breastfeeding (IMD) and exclusive breastfeeding, and monitoring the growth and development of toddlers. In addition, the cadres also stated that they carried out monitoring such as pasting $\mathrm{P} 4 \mathrm{~K}$ stickers at pregnant women's houses and always reminded them to immunize infants and toddlers, as stated by the informants as follows:

"The health of mothers and children is that we monitor especially pregnant women from the golden period, which is from gestational age to delivery. After giving birth, especially our cadres, we monitor where the pregnant women are after giving birth and we monitor the baby 
and we recommend exclusive breastfeeding. Before doing that, from that observation, we also advised to do Early Breastfeeding Initiative (IMD) at the time of delivery. We hope that early initiation of breastfeeding after the birth of the child is monitored so that the immunization is complete, namely the first with $\mathrm{HBO}$ until the age of 9 months. So our task as cadres for both pregnant women and toddlers is that from the first time we were pregnant we have monitored it by pasting the P4K sticker at the pregnant woman's house. After giving birth, we reminded that the injection after delivery was HBO and carried out Early Initiation of Breastfeeding." (I2)

\section{b. The Role of Cadres in Implementing Integrated Healthcare Center during the Covid-19 Pandemic}

Based on the research results, all informants stated that they had received socialization about Integrated Healthcare Center operations during the Covid-19 pandemic. The socialization was given by the Coordinating Midwife and Nutrition Officer during a cadre meeting at the Kampung Bali Community Health Center, Pontianak. The socialization material was provided in accordance with the Integrated Healthcare Center operational guidelines issued by the Ministry of Health, including Integrated Healthcare Center cadres who carry out Integrated Healthcare Center must be healthy, use masks and gloves, wash hands, and use disinfectants such as hand sanitizers.

"There was a socialization regarding Integrated Healthcare Center during the Pandemic, which was carried out by us from the Community Health Center yesterday with the midwife and the mother from nutrition department. The socialization was about cadres who come to be healthy, wear masks, gloves, we wash our hands first and use hand sanitizer." (Main informant 1)

"We also provided socialization to them (cadres) regarding the operational implementation of the Integrated Healthcare Center during the Covid-19 period according to the guidelines from the Ministry of Health, for example, both during meetings and during Integrated Healthcare Center visits, cadres must be healthy and continue to implement health protocols." (Supporting Informant 1)

\section{1) Pick-up method}

Based on the results of interviews with informants, the implementation of Integrated Healthcare Center during the pandemic is prohibited because it causes mass gatherings, the government urges not to gather so that the Integrated Healthcare Center continues to run, cadres carry out ball pick-ups or sweeps by coming to people's homes to monitor the health of infants and toddlers.

"In this pandemic, we are advised by the local government not to gather, but our reports are still submitted to the service and one of the innovations is that cadres continue to go down to the community, namely picking up balls so they carry weights and measure height around themselves." (Main Informant 1)

"In 2020, from January to February, we still opened Integrated Healthcare Center. After the March pandemic, we were forbidden to open. April, May, June and July can only do pick-up method. It is in July, all of our cadres went to the houses of pregnant women and toddlers at the Integrated Healthcare Center." (Main Informant 2)

The implementation of the Integrated Healthcare Center by doing pickup method carried out by the cadres includes weighing, measuring height, filling KMS, giving vitamin A or drugs such as worming, providing nutritious food/snacks, and providing health education, as stated by the following informants:

"We weigh, we measure height, we also provide socialization to toddlers if they are malnourished, what should they eat, if there is stunting, we are underweight, we give socialization about food or the menu should be like this." (Main Informant 1)

"Usually we do pick up method and come home and give vitamin $A$ and 
deworming medicine to children" (Key Informant 4)

"The service at our Integrated Healthcare Center is especially famous for its porridge, so we cook rice porridge with potatoes, chicken, spinach, grated carrots, so if we go we can't take it, so what we can't give BMT at our Integrated Healthcare Center is for infants and toddlers or we do pick up, that's the only difference, but we still carry out weighing and height weighing." (Main Informant 2)

\section{2) Implementation of Health Protocols in the Implementation of Integrated Healthcare Center}

The implementation of the Integrated Healthcare Center by door to door to people's houses during the Covid-19 pandemic was carried out by cadres while still implementing health protocols. The informants stated that the implementation of the health protocol was carried out by always wearing a mask, washing hands, and keeping a distance. Weighing and length/height measurement tools are also always disinfected if they have been used by one person, as stated by the following informant:

"During the pandemic, we always keep our distance as long as there is no gathering, the Integrated Healthcare Center does exist but we always do pick up during this pandemic, we always keep our distance to wash our hands and continue to use health protocols." (Main Informant 1)

"Messages from the Community Health Center is that we must follow health protocols, so we have to wear masks, wash our hands, keep our distance and spray disinfectant when we use one baby to another baby, clean it first, lest we or the toddlers we visit can be exposed to Covid. (Main Informant 2)

\section{c. The Role of Cadres in Monitoring Maternal and Child Health During the Covid-19 Pandemic}

Based on the interview results with informants, monitoring the health of pregnant women and children in the Community Health Center (Kampung Bali) working area during the Covid-19 pandemic was assisted by cadres. Cadres were asked to provide data to the Community Health Center if there are pregnant women in their area and invite pregnant women to come to it if they have never had a health check, make a referral to the Community Health Center if there is an emergency for pregnant women, the informant also stated that pregnant women who did not come to the Community Health Center During the Covid-19 pandemic, blood-enhancing tablets $(\mathrm{Fe})$ were given, as stated by the following informant:

"For pregnant women, there is assistance from the Community Health Center. We collect data, for example, what age is this pregnant woman, we will check the data with Maternal and Child Health Book, so what is already in the data is what we ask to come if you have never been checked and usually the cadre asks to bring a photocopy of the KK and the KIA book." (Main Informant 1)

"Usually, pregnant women who don't go to the Community Health Center are given tablets to add blood, and some do not want to take it and we remind them constantly, recommending maintaining cleanliness too, if there is anything we refer to the Community Health Center." (Main Informant 8)

Monitoring the health of infants and toddlers carried out by cadres is by reporting to the Community Health Center if there are cases of sick children with Covid19, children with BGM or with other diseases, as stated by the following informant:

"The role of the cadre is to invite and provide input to parents of toddlers to always report to us if there is, for example, a toddler who is sick due to Covid, BGM or other illness, this is the only problem that sometimes they are afraid. So we reported it to the Community Health Center, who finally came to the community's house if someone was afraid." (Main Informant 7) 
"We give directions, for example, if their scales go down, we will tell them that this child must go to the Community Health Center to be checked" (Main Informant 5)

\section{d. The Role of Cadres in Reporting the Results of Integrated Healthcare Center Implementation}

Based on the interview results with informants, the reporting of Integrated Healthcare Center results carried out by cadres is still carried out as usual, namely reporting to the community health center, sub-districts, districts and mayors through the Integrated Healthcare Center Information System (SIP).

"We have to submit a report to the mayor every year, so if our SIP is good, God willing, the results will also be good and our reports must also be in sync." (Key Informant 2)

"Usually every 5th day the Integrated Healthcare Center runs smoothly and for reporting it is usually the head who makes a report and it is given to the community health center, district office, sub-district and mayor." (Main Informant 8)

\section{DISCUSSION}

The research results stated that most of the informants had been given socialization related to the operational implementation of the Integrated Healthcare Center during the Covid-19 pandemic. The socialization was provided by the Community Health Center of Kampung Bali in Pontianak, especially from the coordinating midwife and nutrition officer regarding the operational guidelines for the Integrated Healthcare Center during the Covid-19 pandemic. Integrated Healthcare Center implementation by taking into account several conditions such as Integrated Healthcare Center cadres must be healthy, continue to carry out health protocols such as wearing masks and gloves, washing hands and maintaining social distance.

During the Covid-19 pandemic, immunization services either at Integrated
Healthcare Center, community health center, mobile health centers and other health facilities that provide immunization services follow local government policies ${ }^{3}$. Prevention of Covid-19 can be done by diligently washing hands with soap in running water, keeping a distance from people when talking, not touching your face with dirty hands. It is also recommended to wear a mask and cover the nose and mouth with a tissue or bent elbow when coughing ${ }^{10}$.

Based on the interview results, the informants' knowledge about maternal and child health is by providing health services from pregnant women to childbirth, providing counseling on Early Initiation of Breastfeeding (IMD) and exclusive breastfeeding, and monitoring the growth and development of toddlers. Integrated Healthcare Center cadres also stated that the health of mothers and children during the COVID-19 pandemic was still being carried out by monitoring such as pasting $\mathrm{P} 4 \mathrm{~K}$ stickers at pregnant women's houses and always reminding them to immunize infants and toddlers.

To the present, knowledge about COVID-19 infection in relation to maternal and child health is still limited and there are no specific recommendations for handling COVID-19. Based on these limited data and a few examples of cases in the treatment of previous Coronaviruses (SARS-CoV and MERS-CoV) and some cases of COVID-19, it is believed that mothers and children are at higher risk for serious illness, morbidity, and mortality compared to the general population ${ }^{11}$. Integrated Healthcare Center has a strategic role in achieving government programs in providing services to the wider community that are equal to empowerment, especially mothers who have the potential and interest to carry out health services, especially mothers and children ${ }^{12}$. Monthly activities at the Integrated Healthcare Center are routine activities that aim, among other things, to monitor the growth of toddlers' weight by using the Towards Healthy Card (KMS), providing nutritional counseling, 
and providing basic nutrition and health services $^{13}$.

Based on the research results, informants stated that the implementation of Integrated Healthcare Center during the pandemic was prohibited because it caused mass gatherings, the government urges not to gather so that the Integrated Healthcare Center can continue to run, cadres carry out ball pick-up or sweeps by coming to people's homes to monitor the health of infants and toddlers. The Central Government, in this case the Ministry of Health, socializes how to implement maternal, child and toddler health services through the Mobile Integrated Healthcare Center/Mobile Integrated Healthcare Center. Immunization services can be delayed and require officers (assisted by health cadres) to record children who have not received immunization services to be prioritized at the first opportunity. Health workers need to record and track (defaulter tracking) children who are delayed in immunization due to the Covid-19 pandemic to plan intervention activities (catch ups) as soon as the situation allows. Intervention activities resulting from tracking can be in the form of sweeping, drop out follow-up (DOFU), or crash programs ${ }^{13}$.

Based on the interview results, the cadres stated that they provided health education in the form of counseling when visiting residents' houses (Integrated Healthcare Center participants). The counseling given is usually related to the health of mothers and children. Counseling can be done individually or in groups, such as individual or face-to-face counseling, which can be done at the Integrated Healthcare Center or during home visits, and can also use MCH books, food samples and others ${ }^{14}$.

Monitoring the health of pregnant women and children in the working area of the Community Health Center (Kampung Bali) during the Covid-19 pandemic was assisted by cadres. Cadres are asked to provide data to the Community Health Center if there are pregnant women in their area and invite pregnant women to come to the Community Health Center if they have never had a health check, make a referral to the Community Health Center if there is an emergency for pregnant women, the informant also stated that pregnant women who did not come to the Community Health Center during the Covid-19 pandemic, blood booster tablets $(\mathrm{Fe})$ were given. The role of cadres in maternal and child health is to carry out early detection of maternal and child health problems by using the $\mathrm{MCH}$ handbook. In addition, the cadres are expected to be able to help the families of the mother or child who will be referred in terms of what to bring ${ }^{3}$. The functions and roles of cadres in community mobilization are in terms of: 1) Clean and healthy living behavior (PHBS), 2) Observation of health problems in the village, 3) Environmental health efforts, 4) Improving maternal and child health ${ }^{15}$.

The interview results with informants stated that the reporting of Integrated Healthcare Center results carried out by cadres was carried out as usual, namely reporting to the community health center, sub-district, districts and mayors through the Integrated Healthcare Center Information System (SIP). In an effort to improve and activate the Integrated Healthcare Center program, it cannot be separated from the support of knowledge and technology in the health sector, the Integrated Healthcare Center Information System at the Community Health Center of Kampung Bali Pontianak makes it easier for Integrated Healthcare Center cadres to input or record data on Integrated Healthcare Center visits. The Integrated Healthcare Center Information System for maternal and child health can assist cadres and midwives in carrying out activities at the Integrated Healthcare Center including data collection for mothers and children, weighing toddlers, data collection on pregnant women and data collection on Family Planning of Fertile Couples ${ }^{16}$. 


\section{CONCLUSION}

The interview results provide an overview of the role of cadres in improving maternal and child health during the Covid19 pandemic, which includes the implementation of Integrated Healthcare Center with the pick-up method while still implementing health protocols, monitoring maternal and child health and reporting Integrated Healthcare Center results through the Integrated Healthcare Center Information System. Assistance and training are needed for Cadres such as providing appropriate information to the public regarding the importance of health during a pandemic, especially regarding maternal and child health, health checks for pregnant and lactating mothers and growth and development of infants, toddlers/children so that optimal health quality can be achieved.

\section{Acknowledgement: None}

\section{Conflict of Interest: None}

\section{Source of Funding: None}

\section{Ethical Approval: Approved}

\section{REFERENCES}

1. Ministry of Health of the Republic of Indonesia. (2012). Indonesian Health Profile. In Ministry of Health Indonesia

2. Gandhi, M., Yokoe, D. S., \& Havlir, D. V. (2020). Asymptomatic Transmission, the Achilles' Heel of Current Strategies to Control Covid-19. New England Journal of Medicine. https://doi.org/10.1056/nejme2009758

3. The Indonesian Ministry of Health. (2020). Technical Instructions for Immunization Services During the Covid19 Pandemic. In Covid-19 Ministry of Health.

4. Amrina, A., Ramadhan, B., Amar, N., \& et al. (2020). Implementation of Posyandu Activities during the Covid-19 Pandemic as an Effort to Fulfill the Rights of Toddlers and Pregnant Women in accordance with the Recommendations of the Ministry of Health of the Republic of
Indonesia in Bongkok Village, Kramat District, Tegal Regency. Angewandte Chemie International Edition, 6(11), 951952., 2013-2015.

5. Mar'ah, E. M. (2020). Pay for Maternal and Child Health Services during the Covid-19 Pandemic. Indonesian Journal of Community Health Nursing.

6. Indrawati, L., \& Tjandrarini, D. H. (2018). The Role of Health Service Indicators to Increase the Value of the Reproductive Health Sub-Index in the Community Health Development Index (IPKM). Health Research and Development Media, 95-102.

7. Slamet, S., Azizah, A. N., \& Muzaki, I. A. (2021). Implementation of "Mobile Posyandu " During Pandemic Covid 19. 1(1), 315-320. https://expert mediapress.com/proceedings/index.php/ici stech/

8. Meilyana, E., Karo, M. B., Indrawati, L., \& Peraten, A. M. (2020). Education on the Use of Posyandu Services after the Covid19 Pandemic Enters the New Normal Period in Improving Public Health. Scientific Journal of Community Service.

9. Tristanti, I., \& Khoirunnisa, F. N. (2018). Performance Of Health Careers In Implementation Of Posyandu In Kudus District. Journal of Nursing and Midwifery Science. https://doi.org/10.26751/jikk.v9i2.470

10. World Health Organization. (2020). World Health Organization - Situation Report-51. Coronavirus Disease 2019 (COVID-19).

11. Rahmi, J., Romlah, S. N., Listiana, I., Handayani, P., Darmayanti, D., Arimurti, I. S., Holidah, H., \& Kasumawati, F. (2020). Maternal and Child Health in the Era of the Corona Virus Disease (Covid19) Pandemic. Hours: Journal of Community Service.

12. Yafie, E., \& Haqqi, Y. A. (2019). Development application "detection of growth and development for new born until two years" based on android. International Journal of Recent Technology and Engineering. https://doi.org/10.35940/ijrte.B1110.0982 S919 
Daevi Khairunisa et.al. The role of integrated healthcare center (posyandu) cadres in increasing maternal and child health during COVID-19 pandemic.

13. Ministry of Health RI. (2017). Guidelines for the Implementation of Posyandu.

14. Ministry of Health RI. (2013). Posyandu health cadres Towards Nutrition Awareness Families. Indonesian Ministry of Health, Director General of Nutrition and Maternal and Child Health.

15. Ministry of Health RI. (2007). Cadre and Toma. Husada devotion.

16. Primary, S. (2016). Implementation of the Mawar Posyandu Information System in
Simpang Empat Village. Technologia, 7(4), 237-244.

How to cite this article: Daevi Khairunisa, Nurhasanah, Tria Susanti et.al. The role of integrated healthcare center (posyandu) cadres in increasing maternal and child health during COVID-19 pandemic. International Journal of Research and Review. 2022; 9(2): 98-106. DOI: https://doi.org/10.52403/ijrr.20220214 